\title{
3 \\ Comic books, science (fiction) and public relations
}

\section{Ian Horton}

\section{Introduction}

Comic books have a long but mostly unwritten history in the field of public relations yet they have had a significant impact on society throughout the twentieth and into the twenty-first century. Notable British examples from the 1980s included: AARGH! (Artists's Against Rampant Government Homophobia) created to protest against Clause 28 of a government bill banning the 'promotion' of homosexuality, Strip Aids designed to raise awareness of Aids and Raymond Biggs' anti-nuclear weapon graphic novel When the Wind Blows (Sabin, 1993:102-4). In the early 1980s the Department of Health created an anti-smoking campaign that pitted DC Comics Superman against the supervillian Nic O'Teen and more recently comic books have been extensively used in health campaigns across the world, a development that has received some critical attention through the emergence of the Graphic Medicine network and associated conferences for both academics and practitioners. ${ }^{1}$ 


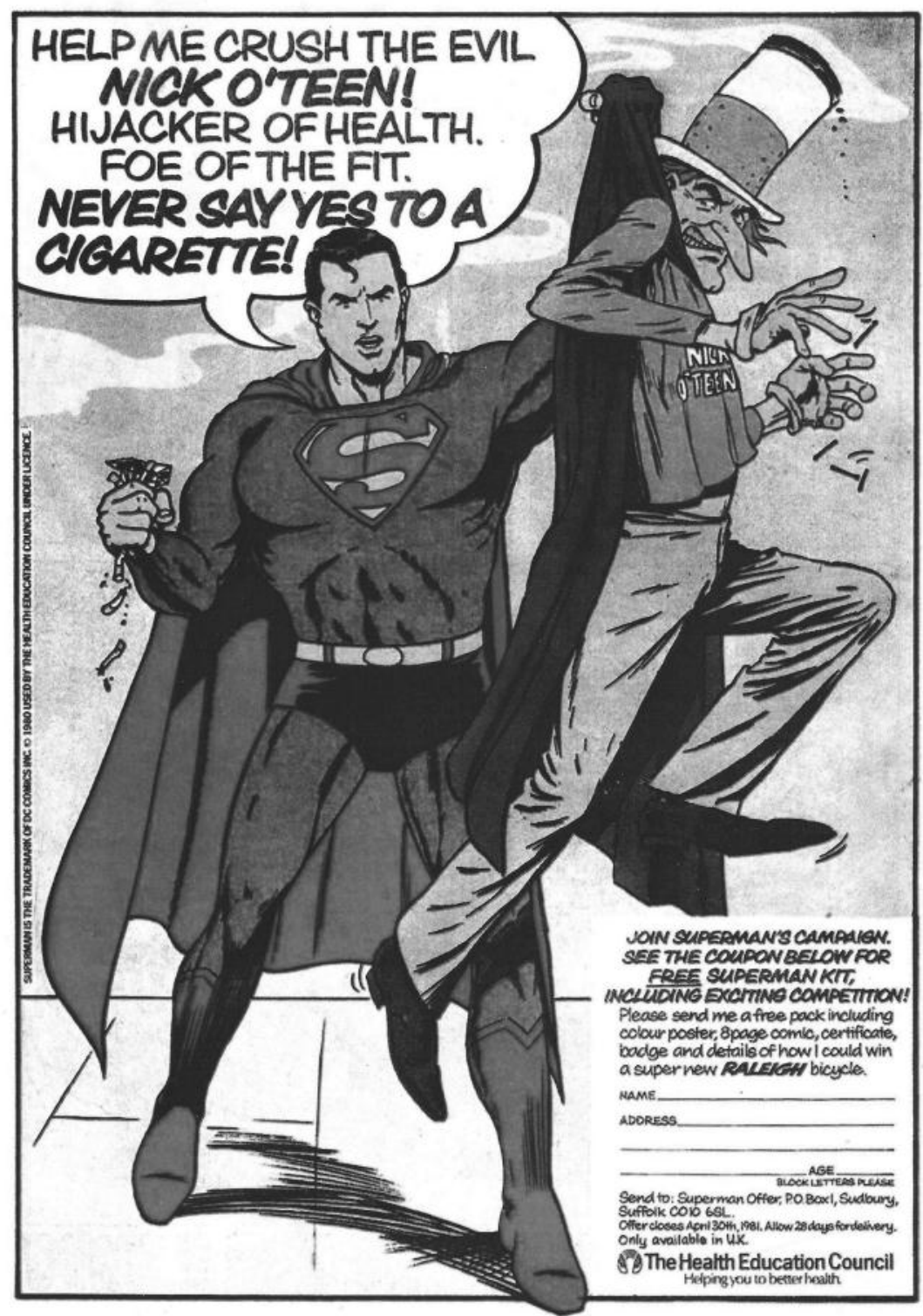

Figure 3.1 Advertisement Superman Vs Nick O’Teen, Health Education Council, Department of Health, United Kingdom, 1980.

(C) Crown copyright.

Public relations comic books are just one sub-set of a wider field of practice that comic book artist and theorist Will Eisner has categorised as informational comic books and this study explores how public relations 
comic books differ from those that have a more commercial intent which might be considered as promotional or even belonging to the world of advertising. These terms will be defined specifically in relationship to ideas of public engagement using comic books from a range of different genres before focusing on examples from science (fiction) and concluding with a detailed examination of two recent examples in the public relations field The Asteroid Belter: The Newcastle Science Comic and Dreams of a Low Carbon Future both published in 2013.

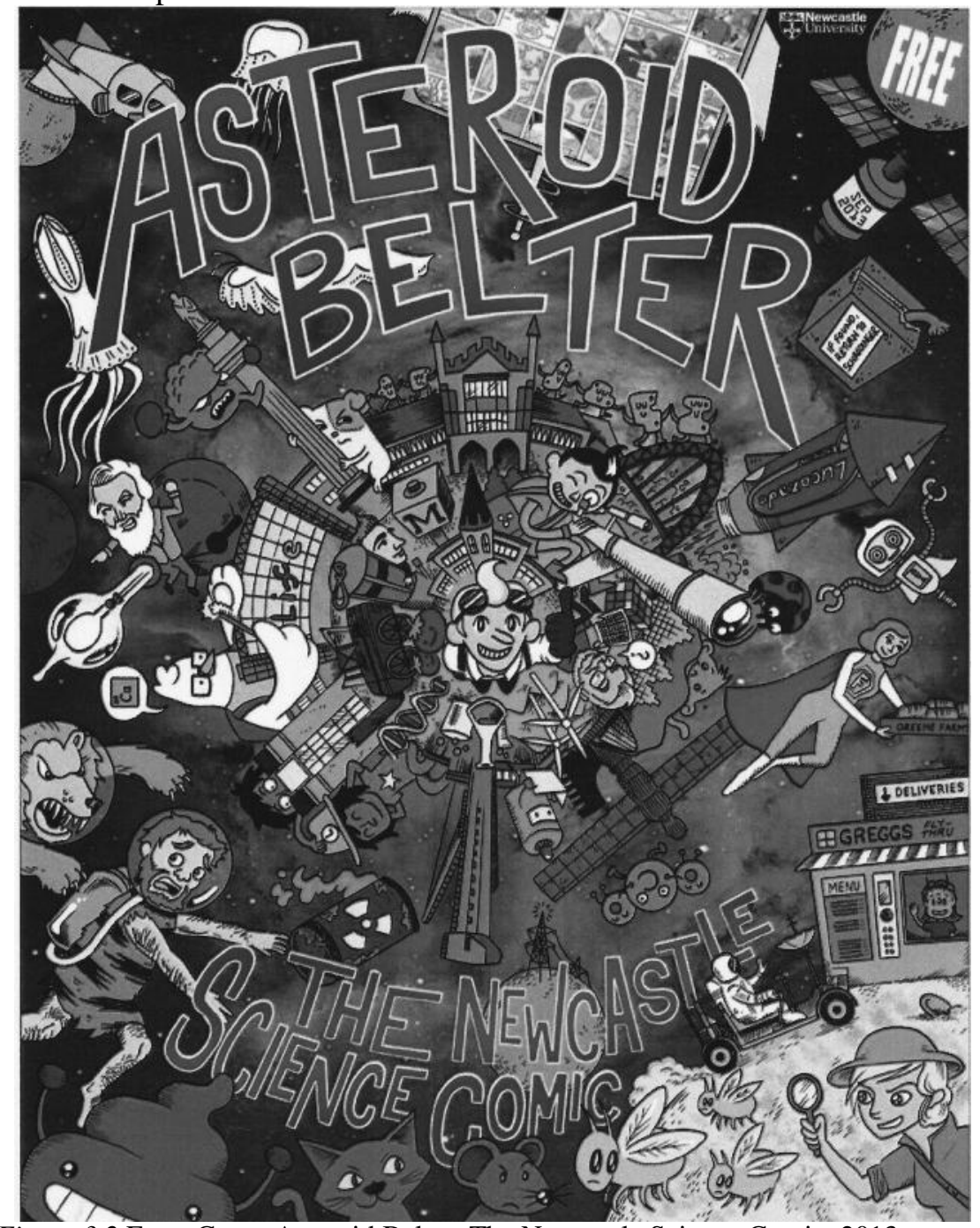

Figure 3.2 Front Cover Asteroid Belter: The Newcastle Science Comic, 2013

(Art: Jack Fallows) 


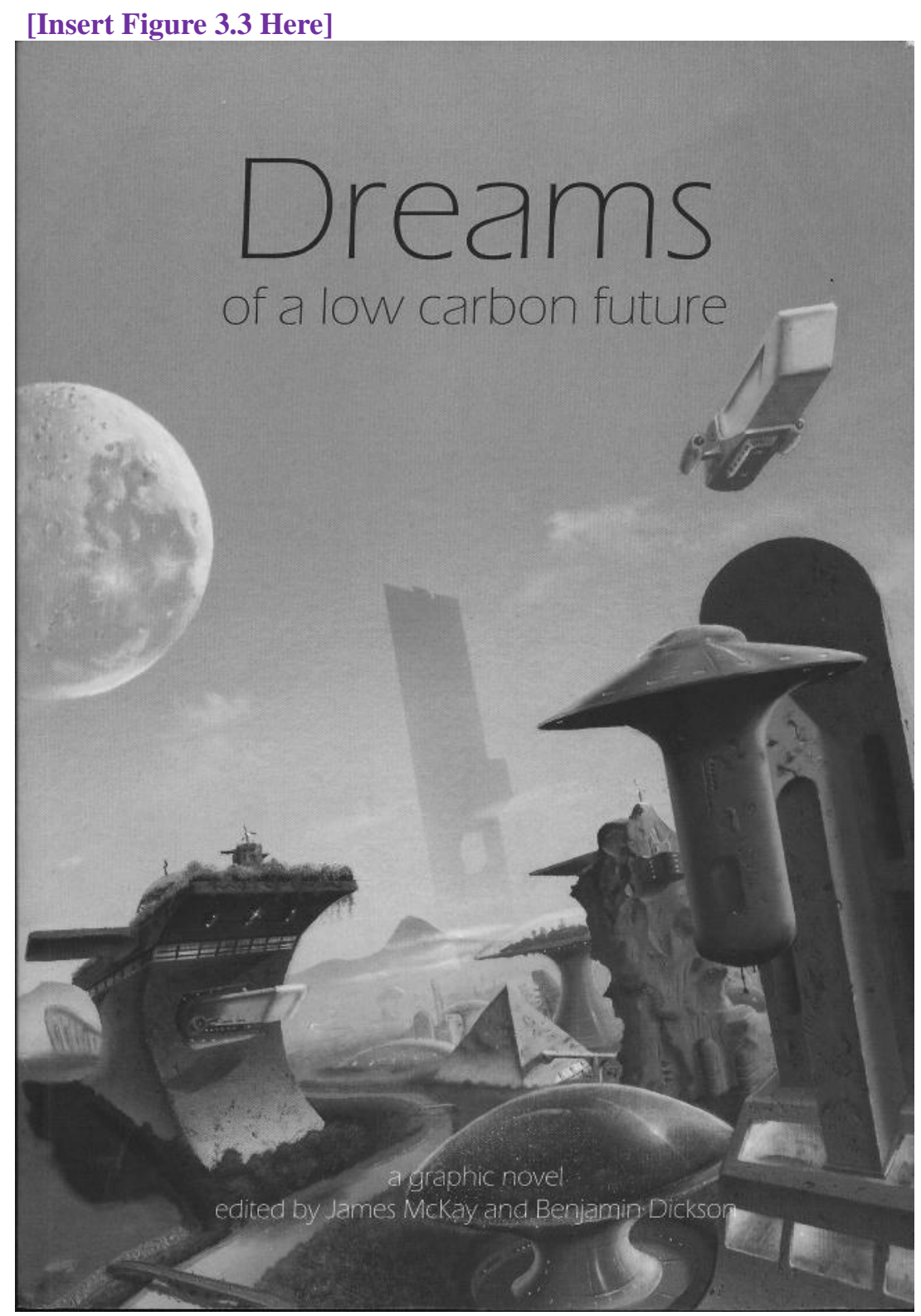

Figure 3.3 Front Cover Dreams of a Low Carbon Future, 2013

(Illustration: Mark Wilkinson, Design: Benjamin Dickinson)

The science-fiction genre has been a mainstay within British and American comic books since the 1930s, by focusing on examples of 
promotional and public relations comic books within this genre it is possible to explore how the tropes and conventions developed for entertainment purposes operate when used for different aims and objectives. The two main examples examined here are anthology comic books that build on a peculiarly British tradition in containing many short individual stories rather than one long narrative running throughout and were designed to engage schoolchildren of various ages in science based issues and topics. Dreams of a Low Carbon Future was produced by the engineers of the Doctoral Training Centre in Low Carbon Technologies at the University of Leeds with ESPRC funding to examine and promoted solutions to climate change. Asteroid Belter was produced as part of the British Science Festival held at Newcastle University in 2013 and was aimed at a younger audience to promote engagement with science as a topic more generally. The different modes of address employed in these examples will be explored in detail allowing for an examination of the complex relationships between illustration, information design and comic books when engaging with audiences. In addition to employing communication methods more commonly used in graphic design these different modes utilise features such as direct address of the audience to promote the 'truth' of the narratives being told, a device often associated with documentary comics and the space that exists between fictional and factual accounts of events (Mickwitz, 2016). This formal analysis concludes by considering of the notion of impact and public engagement and why comic books are such a valuable potential tool for the public relations profession.

\section{Defining the field of public relations comic books}

Although in the last twenty years Comics Studies has emerged as a distinct academic discipline there are still many aspects of the field that have received little critical attention and public relations comic books are one such neglected area. ${ }^{2}$ In his article The Funnies' Neglected Branch: Special Purpose Comics Sol M. Davidson notes that

'The amazing thing is with all the millions of special purpose comics reaching and influencing their targeted audiences, that this comics genre is the least researched, appreciated, or collected branch of comic art.'

(2005: 340$)^{3}$

For Davidson, Special Purpose Comics is a broad category that includes 'Biography, Economics, Education, Entertainment, Government, History, Public Relations, Recreation, Religion, Sales, Science, Training, etc.' (2005: 340). His study includes many examples relating to these and other categories but there is little evaluation of the substantial differences that exist between them or of the similarities that cut across these fields. Public 
relations comic books form only a small part of Davidson's study and because they have generally received little attention there is a lack of precision in defining what exactly might count as belonging to this particular field. Davidson does however note that other terms have been used for these kinds of comic books.

'Other descriptive titles have been used to describe this neglected genre giveaways, industrial comics, premiums, promics, promos. The Comic Book Price Guide uses the term promotional comics, and indeed, each comic was created to promote an idea, (Eat Right to Win), a product (Chevrolet Fun Book), or a purpose (Making a Home for Wildlife). Not entirely in jest, we propose the term impact comics for that describes their intent and, in large measure, their success ... In every case, someone or some organization had a goal to accomplish, an objective to be attained - an election campaign to be won, a product to sell, a lesson to be taught, the environment to be saved - and some savvy, energetic risk-taker put his/her money into producing a graphic arts product that would help reach that goal.' (2005: 340).

The notion of impact is important for Davidson and suggests such comic books should be judged by their effectiveness in achieving their aims rather than by considering the visual and narrative structures employed. Measuring the effectiveness of any campaign tool is always difficult but an example from 1948 demonstrates the potential of public relations comic books. The American President Harry S. Truman was running for re-election but was well behind in the polls to his Republican opponent Thomas E. Dewey. Realizing the severity of the situation the Democratic Party National Committee took the bold step of commissioning a sixteen-page biography titled The Story of Harry S. Truman. Three million copies of this rather sanitized and hagiographic biographical comic book were distributed to the core demographic of the Democratic Party and Truman went on to win the election by over one million votes (Smith and Duncan, 2009: 269-70). This causal link is difficult to prove but it is worth noting that in the decades that followed political parties in America used comic books for a number of different tasks such as educating and motivating voters, besides the most obvious application of attempting to win elections, which suggests that at the very least they believed public relations comic books could have a direct impact on the public (Davidson, 2005: 341-2, 356).

Davidson's term 'impact comics' has not been widely adopted but it does have some value when considering the aims of public relations comic books and can additionally be applied to other comic book genres. When examining the concept of genre in relation to mainstream comic book production Duncan and Smith confusing state that 'Usually distributed as giveaways, promotional comics help to advertise a product or a conviction or are a reward for having made a purchase' (2009: 216) In compounding advertising and promotional comic books they highlight the shared qualities of such publications but do not distinguish the substantial differences that 
exist between them in terms of purpose and intent. There is a considerable difference between creating a comic book to directly advertise or promote a product and one that wants to raise awareness of a conviction and it is the latter that is the focus of this study.

From the 1960s to the 1990s single-page advertising, promotional and public relations comic strips were often included in British boy's anthology comic books alongside the main adventure stories in the genres of action, sport and war. By examining examples of these comic strips in detail it is possible to differentiate between advertising, promotional and public relations comic books by highlighting their similarities and differences. An issue of the boy's adverture comic book Valiant from February 1971 contained three such strips, the first of these was an advert for a range of plastic model kits titled 'Airfix in Action' that employed comic book devices such as panels and speech balloons but did not strictly speaking tell a story but instead showcased the different model kits available. ${ }^{4}$

A second example from this issue contained a full page adventure story titled 'Kit Carter's Clarks Commandos' in which a group of teenage boys (the Clarks Commandos) find an injured bank robber and turn him over to the police, only in the final panel is there any reference to the Clarks' product line with an image of the shoes and the tag line 'Commandos are action shoes for tough assignments'. The final example from this issue of Valiant told the true life story of 'Brian Downey! Marine Commando!' who aged 17 quit his job as a miner in Newcastle and joined the Royal Marines. The final panel included the caption 'At 25 Brian's seen most of the world from snow warfare exercises in Norway to jungle training in Johore Bahru, His next assignment? The Bahamas!' 5

At one level this can be seen as a recruitment drive by the Royal Marines and the readers were encouraged to send away for the free Royal Marines booklet 'Britain's Commandos' but the juvenile readership of Valiant would have been too young to enlist and this comic strip is more readily conceived as a case of maintaining public relations with potential future recruits and raising awareness of the Royal Marines as a potential career choice. All three examples from Valiant employed the conventions of boy's comic book action and war stories to engage with readers but only the final one can be considered as an example of public relations as the others focus more on directly promoting or advertising products.

\section{The origins of public relations comic books}

There is a long history of American comic books being used for advertising purposes and it is this area we can detect the origins of the medium being used for public relations. As early as 1933 Fortune magazine devoted an article titled 'The Funny Papers' to the significant role comic strips played in newspaper sales highlighting the fact that most adults were regular readers 
of the 'Funnies' as these comic book newspaper supplements were called (1933: 44-9, 92, 95-6, 98, 101). The final section of this article focused on the emergence of advertising comic strips noting that in 1932 Comic Weekly sold over $\$ 1,000,000$ of advertising space and highlighted some of their key characteristics

'The advertising strips have a close superficial resemblance to the genuine funnies although they are built around a sales talk instead of a gag. They are nearly always based on the Before and After theme. Their type is the oldfashioned (except that it seems not so old-fashioned) hair-restorer advertisement showing an absolutely bald surface before using the marvellous remedy and a luxuriant hair growth afterwards. Sample: Betty is pictured in tears because Jim does not call on her anymore. The other girls, sympathetic, contrive in some sweet, girlish way to insinuate that Betty has been "careless" and does not wash her underthings every day. This idea percolates and Betty is shown in the act of washing. In the last panel Jim is back again and cleanliness appears to be next to matrimony. This is a Lux advertisement.'

These newspaper comic strips were created to advertise products through direct persuasion techniques an approach that was much derided in the Fortune article for undermining the values of the advertising and marketing professions. At the same time as these newspaper strips emerged in America a parallel development saw the creation of what were called at the time advertising premium comic books but which are better considered as examples of public relations comics. The originator of the premiums was Harry I. Wildenberg who worked as a sales manager at the Eastern Colour Printing Company. In the early 1930s he realised that it was possible to use spare printing capacity at the company to produce cheap comic books which could then be given away free to customers as a premium. Gulf Oil were the first to take up this idea and gave these comic books away at their gas stations and Wildenberg, with the help of another salesman M. C. Gaines, attracted a range of other companies for whom they produced premiums.

These other companies included Proctor and Gamble, Canada Dry, Kinney Shoes and Wheatena as well as a host of others that sold children's products, the comic books were generally produced in print runs of 100,000 to 250,000 but on occasion could reach runs of 1,000,000 copies. These premium comic books did not directly advertise the products but instead raised brand awareness and created band loyalty. These premiums had a major impact on the American comic book industry. In 1934 realising the popularity of these premiums Wildenberg and Gaines convinced the American New Company to distribute a 64-page comic book titled Famous Funnies at newsstands with a 10 -cent cover price. Although not initially a 
success by Issue 12 Famous Funnies was making a substantial profit and other publishers soon followed their lead thus marking the beginnings of what became the American entertainment comic book industry (Goucart, 1991: 18-20).

Will Eisner was a key figure in the American comic book industry, as both a practitioner and theorist, who produced comic books for both entertainment and public relations purposes. Eisner was a highly successful comic book artist in his own right, producing the celebrated detective newspaper strip The Spirit in the 1940s and 1950s before leaving mainstream comic books to focus on the instructional and educational comic books he produced for The American Visual Corporation which he had founded in 1948 and whose clients included RCA Records, Baltimore Colts and the New York Telephone. He returned to the comic book industry in the 1970s going on to produce several semi-autobiographical graphic novels, such as A Contract with God.

In addition to his comic book work Eisner published several influential instructional books on the process of making comic books, these included Comics and Sequential Art in which he divided comic books into those created for entertainment purposes and those created to be instructional although he did stress that these two kinds of comic books can merge and crossover (1985: 153). He further differentiated instructional comic books into attitudinal and technical, where the technical comic books focused on conveying how a task can be executed precisely and efficiently. When discussing the potential for comic books to promote attitudinal change Eisner noted that

'Another instructional function of sequential art is conditioning an attitude towards a task ... People learn by imitation and the reader in this instance can easily supply the intermediate or connecting action from his or her own experience. Here too there is no pressure of time as there would be in a live action motion picture or animated film. The amount of time allowed to the reader of a printed comic to examine, digest and imagine the process of acting out or assuming the role or attitude demonstrated is unlimited.'

(1985: 153-4)

To demonstrate this point Comics and Sequential Art included some examples of Eisner's own work produced for the State Employment Service by his company The American Visual Corporation. The main series he produced for them were nine full colour eight-page booklets collectively titled The Job Scene that looked at areas such as retail sales and health care with a view to explaining employment opportunities to students. They also produced comic books titled The Power is Green and You're Hired that looked respectively at gaining the necessary skills for employment and how to keep a job once employed (Davidson, 2005: 350-1). 
Eisner's most significant and long-lasting client for The American Visuals Corporation was the U.S. Department of the Army for whom he created PS Magazine the Preventative Maintenance Monthly producing 229 issues between 1951 and 1972. ${ }^{6}$ The comic book strips included in this magazine served two functions, at one level they were purely functional in instructing soldiers how to maintain and use their equipment, at another level these stories were meant to entertain and therefore intended to create attitudinal change amongst service men by engaging them with the tasks in hand. ${ }^{7}$ 


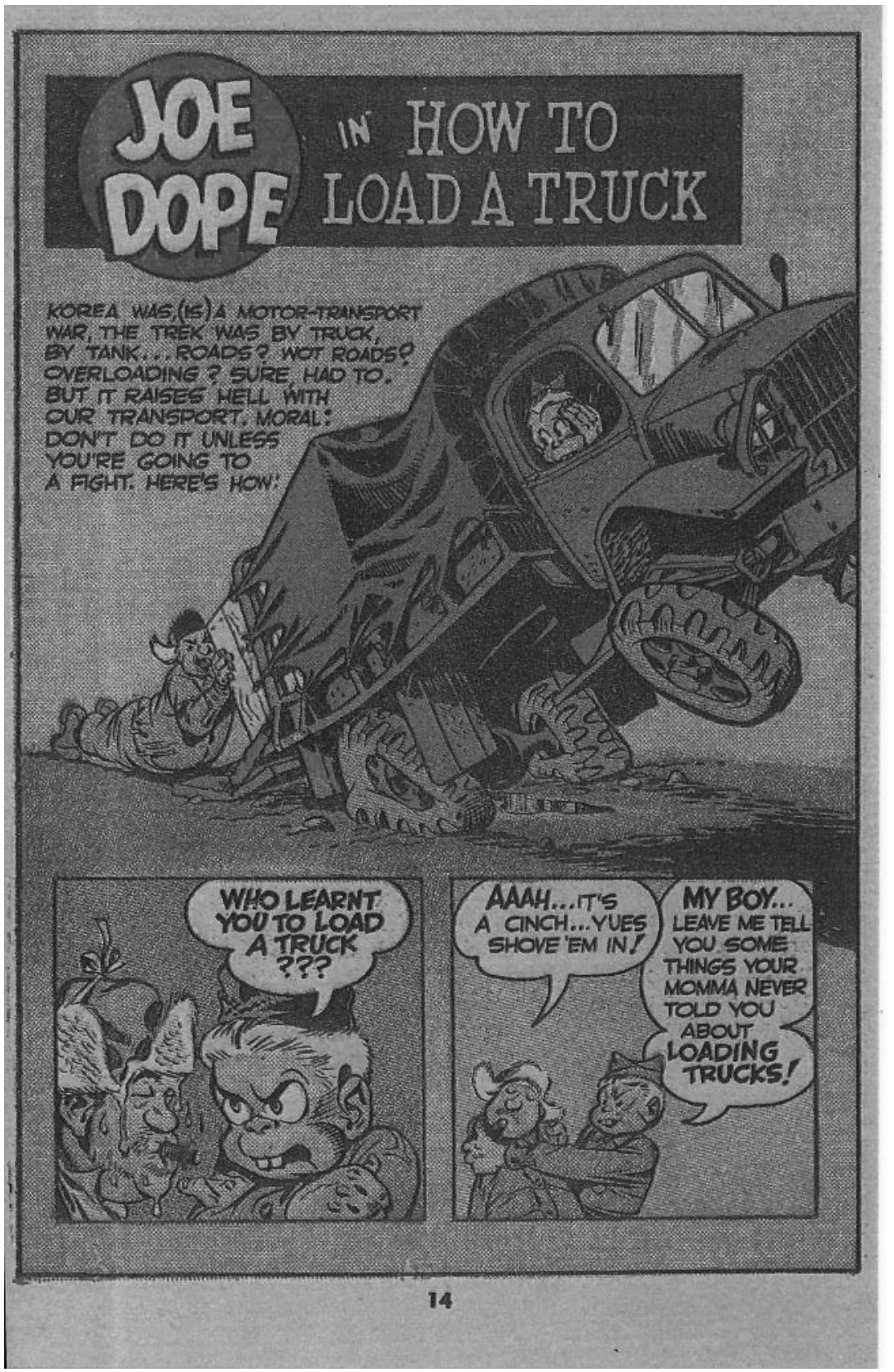

Figure 3.4 Will Eisner ‘Joe Dope in How to Load a Truck’ PS Magazine June 1951 Vol 1 No. 1 p. 14. 


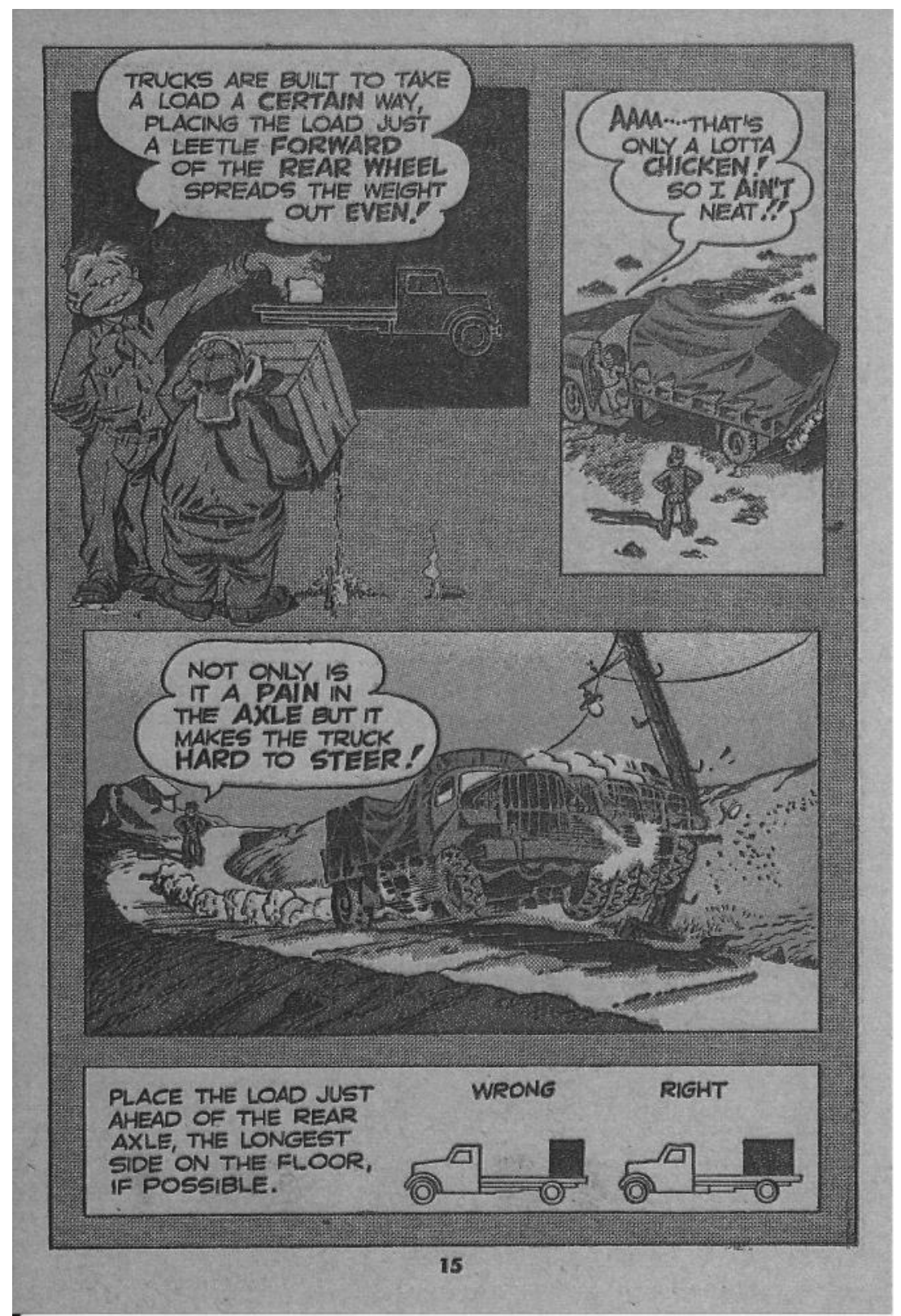

Figure 3.5 Will Eisner ‘Joe Dope how to Load a Truck’ PS Magazine June 1951 Vol 1 No. 1 p. 15.

The main character employed in these comic strips was Joe Dope who had started out as a rather dumb soldier in some of Eisner's earlier war stories but was transformed into the 'hero' in the PS Magazine stories. In the story 
titled 'Joe Dope in 'How to Load a Truck" from the first issue of the magazine we see Joe Dope berating another private for his lack of care in treating the army's equipment. The visual style was cartoonish and this, alongside the use of humour and colloquial language, it was hoped would allow the reader to engage more fully with the message being communicated. The strip also used infographics, diagrams and more realistic visual styles to give variety to the narrative and provide more accurate information on the task being explained (Fitzgerald, 2008).

The American armed services had already utilized comic books for public relations, all be it with a propaganda dimension during the Second World War (Chapman, Hoyles, Kerr and Sheriff, 2015: 101-24). In 1942 the Graphics Division of the Office of War Information commissioned research by the advertising agency Young and Rubican into how to produce effective posters to communicate the war effort. One of their recommendations was that comic strip elements should be included in the posters as this would allow for empathy and identification with recurrent characters. Although the Office of War Information did not produce their own comic books in this period they did closely monitor the content of commercial comic books and strips and sent out a monthly guide to newspaper, magazine and comic book publishers about what constituted suitably patriotic content (Chapman, Hoyles, Kerr and Sheriff, 2015: 101-24).

One publisher Magazine Enterprises uniquely produced two war comic books United States Marine Corp and The American Air Forces in close collaboration with the armed services using photographs they provided in narrative sequences and as source material for comic strip illustrations. Interestingly United States Marine Corp included two humorous recurring characters, Monte and Trip, in a similar vein to Eisner's Joe Dope and presumably with the same aim of creating identification and empathy.

Magazine Enterprises, as the name suggests, was a commercial publisher and since the earliest days of the comic strip well known recurring characters had been used to advertise products (Davidson, 2005: 350-1). In the 1970s DC Comics by then a subsidiary company of Warmer Communications, decide to monetize their main superhero characters for advertising, promotional and public relations purposes. This activity was itself promoted in a brochure DC Comics produced in 1979 that showed the superheroes themselves making promotional comics and included tag lines such as 'Let us start working for YOU!' and 'The graphic way to present your marketing message'. The brochure listed over 30 companies and organisations that had successfully used comic books and many of these, such as General Electric, MacDonalds and Pizza Hut, would have used them mainly for marketing and advertising.

However, other organisations listed like, the Anti-Defamation League, the National Mental Health Association and the United States Public Health Commission would have no product as such to sell so would have been 
using them primarily for public relations. The brochure furthermore drew on support from the advertising and marketing industries with supportive quotes from publications such as Advertising Requirements and Sales Management. A quote from Premium Practice and Business Promotion included in the brochure stated 'Few premiums can rival the wide acceptance enjoyed by comics amongst our kids - or the variety available to the advertiser who uses them to promote his products'. This reveals the main of use of these comic books as free giveaways with promotional intent and indicates that the industry was taking the medium seriously as a public relations tool.

The fact that DC Comics not only licensed the superhero characters but also created the artwork ensured that the brand was not damaged by the resulting comic books. Although not a comic book the series of posters created by DC Comics for the British Health Education Council in the early 1980s show the creativity this afforded in action (see Figure 3.1). These antismoking posters pitted Superman against a specially created new character Nick O'Teen whose uniform consists of a dingy tar-soaked brown cap and suit with a smoking cigarette butt on his head. Nick O'Teen's crumpled figure is in stark contrast to the brightly-coloured Superman who lifts Nick O'Teen with one hand while crushing a packet of cigarettes in the other proclaiming 'Help me crush the evil Nick O'Teen! Hijacker of health, foe of the fit. Never say yes to a cigarette!'

From this brief history of public relations comic books it is clear that they were from the outset closely associated with: the newspaper advertising strips that proceeded them, free giveaway 'premiums' and the emergence of the American comic book as a mainstream medium in the 1930s. Of course, public relations comic books did share some of the aims of advertising, promotional and mainstream comic books in terms of engagement which is why later companies such as DC Comics were able to monetised their most popular characters for public relations purposes. However, Eisner's work and theories demonstrate that the biggest difference between these different kinds of comic books is that those created for public relations were focused on achieving attitudinal change in their audiences.

\section{Comic books, science (fiction) and public engagement}

In examining contemporary public relations comic books that promote the sciences using the science fiction genre it is important to establish some of the key conventions in this genre and consider how they have been represented previously in comic book form. Comic books and magazines played a key role in communicating scientific knowledge and technological innovation in Britain following the Second World War. ${ }^{8}$ From the 1950s onwards British comic books such as; Eagle, Robin and Swift, and children's magazines; Look and Learn and World of Wonder, employed visual strategies that synthesised illustration, information design and the narrative 
form of comic books in providing a positive image of scientific achievements. ${ }^{9}$

The relationship between illustration, information design and comic book conventions in these examples can be complex but in its most basic form it can be seen in directional arrows that guide the viewer through the narrative construction of a confusing series of comic book panels. However, some of the most compelling uses of information design in these examples were when these devices were employed alongside illustration and comic strips in the communication of historical, scientific and technological knowledge. Look and Learn and World of Wonder covered these scientific and technological topics with an educationally focused agenda which was made evident in David Stone's 'Editorial' to the first issue of Look and Learn

'Look and Learn is not a comic, or a dusty old encyclopaedia pretending to be an entertaining weekly paper. It is really like one of those fabulous caravans that used to set off to strange and unknown places and return laden with all sorts of wonderful things ... Today, the world changes at a rate undreamt of even by our mothers and fathers ... Of necessity, newspapers and television must adapt themselves to today's frantic pace, and many of us find ourselves bewildered by ever-changing headlines rushing by like racing cars at Silverstone. Many people, tiring of newspapers, turn to papers which thrive on what is called "escaping." ... Between these two extremes there must be what the Ancient World called the Golden Mean, and what we would call a happy medium. A happy medium means a nice balance between fact and fiction, between information and entertainment, between, if you like, laughter and tears. It is our hope that Look and Learn will be the most happy medium of all. But you must be the judge of that.'

(Holland, 2006: 6-7)

The Eagle, founded with clear didactic purposes in the early 1950s, had similarities to Look and Learn in including cutaway drawings of technological marvels, half-page sporting comic strips on keeping a straight bat and explanatory strips looking at scientific discoveries. One comic strip serialised in the Eagle, 'Professor Brittain Explains', examined the technological innovation of the period such as TIM the talking telephone clock, the mechanics behind London Underground ticket machines and the scientific principles behind radar technology. The pipe-smoking Professor Brittain would explain each week's topic to two school children and in addition to using comic strip features such as panels and speech balloons it employed infrographics, maps and technical drawings. In terms of address Professor Brittain directly talked to the children throughout in lengthy explanatory speech balloons and often in his closing remarks invited empathy with the reader by addressing them directly. The aim of ensuring reader engagement was continued at the end of the strip with the request 
'Any Questions: Please write to Professor Brittain, c/o Eagle, if you have any questions or problems you would like him to deal with.'

Although these examples employ some narrative strategies they were essentially factual in terms of content. There is, however, a significant link to some of the science fiction and fantasy stories that were also published in these comic books and magazines. For example, Frank Hampson's 'Dan Dare: Pilot of the Future' was the flagship comic strip in the Eagle and Don Lawrence's 'The Trigan Empire' was an important comic book element in Look and Learn. These stories of the future and far away worlds framed the illustrated articles and comic strips promoting contemporary scientific and technological innovations, taking them away from the factual and firmly into the world of the imagination. Hampson's artwork on the Dan Dare strip has been described as representing ' . . . the most perfectly realised modernist future in the history of British science fiction.' and notable for ' ... its aestheticization of technology with its sleek and streamlined spaceships and its many functional gadgets' (Chapman, 2011: 63). The strip has also been directly linked to the perception of science and technology in this post-war, a period where

'The future imagined in 'Dan Dare' embodies the idealism of the Festival of Britain where technology is both functional and employed for the benefit of mankind ... It is also for the most part a utopian future'

(Chapman, 2011: 63).

Clearly other comic strips in the Eagle dealing with contemporary science and technology such as 'Professor Brittain Explains' would then have been read in relation to this vision of the future which was framed as full of utopian promise. ${ }^{10}$ The concept of utopia has been a longstanding trope within the science fiction genre and it is possible to trace representations of such visions for the future in contemporary public relations comic books.

The examples of science fiction comic books and children's magazines from the 1950s and 1960s examined above enjoyed mainstream success employing relatively conventional comic book techniques and narrative structures. The 1970s saw new developments with innovative techniques and narrative structures being employed in a range of comic books and graphic novels aimed directly at an adult market. Jean Giraud who worked under the pseudonym of Moebius was an important figure in this development as a writer and artist as well as being co-founder of the French science fiction/fantasy magazine Métal Hurlant. His story Upon a Star from 1983 is typical of his later science-fiction comic book work in its themes if not its creation. The original seven-page version was commissioned by the chairman of Citroen to be given away as a gift to the company's branch managers, as a public relations tool in promoting brand loyalty. Moebius kept the central element of the plot, the 'mythical car', the Traction, 
manufactured by Citroen in the late 1930s, when adapting the original version into the forty-page story Upon a Star for Citroen that then inspired a series of sequels titled The Aedena Cycle (Moebuis, 1988).

In this longer version of the story the two main characters, the mechanics Stel and Atan, are called to repair a refinery, which they find deserted, on an asteroid circling a planet. The asteroid is drawn towards the planet's surface, and crashes destroying their spaceship. After the crash a Citroen Traction is the only form of transport still working and they use this to drive to the only signs of life on the planet. These signs emanate from an immense pyramid surrounded by abandoned spaceships that resemble the minarets of an Islamic city, and a tented encampment containing representative members of all the species in the known universe, all drawn to the planet by the pyramid that grants them eternal life. They have been waiting for a pilot to take them to the 'legendary paradise planet of Aedena'. Stel who has an inner affinity with all mechanical devices is this pilot. He is the only person who can enter the pyramid and as he enters it transforms into an ark spaceship that takes the form of the two chevrons that make the Citroen car badge. The story finishes with Stel apparently guiding the spaceship to Aedena as it heads out into deep space. The Citroen Traction, described by Stel as 'a jewel that can take us to the end of this world!' plays the central role in this story, it is the vehicle that allows them to reach the settlement and is symbolically reinforced in the image of the spaceship that allows them to reach paradise (Moebuis, 1988).

As well as being a public relations tool this story playfully uses the concepts of both utopia and dystopia. Utopia is represented by the paradise of Aedena which the technocrat Stel pilots them towards, its antonym the notion of dystopia is represented by the deserted then destroyed asteroid, the mainly uninhabited planet and the abandoned spaceships. The pyramid that transforms into a spaceship also feeds into dystopian notions of an unknowable technological force. When discussing the representation of technology by Jack Kirby in American superhero comic books Hadfield has noted that

'The phrase the technological sublime indeed suggests an attitude of worshipful awe. It seems to me that Kirby's work reveals a less celebratory, more ambivalent sense of the technological sublime, something more in keeping with how I read Burke's definition of the sublime ... That definition is fearful - or rather fear-based . . . the use of high-tech motifs to represent vast forces that not only are ineffable and awful . . . but also might result in shock, estrangement, or madness.'

(2012: 145-6)

Similar dystopian ideas of shock and awe were present in the graphic novel When the Wind Blows created by Raymond Biggs in 1982. The cover image 
showed the main characters Jim and Hilda, a placid elderly British couple in front of the mushroom cloud of a nuclear missile explosion. The story starts with Jim returning to his home, set in an idealised English countryside, after reading the newspapers reporting the threat of nuclear war in his local library. As the narrative unfolds war is announced and the nuclear strike ensues, Jim follow the government advice on dealing with this eventuality as outlined in the public information booklet Protect and Survive, which was published in 1980 and also employed comic book conventions. What follows is a black comedy that contrasts Jim and Hilda's naive belief that they will survive, by hiding in their hastily constructed self-made shelter using advice from Protect and Survive, with the reality of the radiation sickness that kills them. On its release When the Wind Blows was referenced in a Parliamentary debate on the subject of Britain's military defences

'Defence now means defence against a nuclear attack. The gentleman who produced the document "When the Wind Blows" - I think that it was sent to all hon. Members - did a great service to the House and to the public, who may subsequently have the opportunity of reading the book. It spells out in graphic terms the ridiculous deception that is being played on the British people. I refer to the argument that there is a defence against nuclear weapons. ${ }^{11}$

Although produced commercially for entertainment purposes When the Wind Blows had a significant public relations impact in terms of attitudinal change. The fact that a copy was sent to all Members of Parliament was significant and shortly after this the Labour Party adopted a unilateral nuclear disarmament policy, a course of action that must in part have been a reaction to the story by party members and the public.

Dreams of a Low Carbon Future was produced by the Doctoral Training Centre in Low Carbon Technologies at the University of Leeds in 2013 and designed precisely to create an impact similar to that of When the Wind Blows. ${ }^{12}$ Edited by James McKay and Benjamin Dickinson and funded by the ESPRC and the Royal Academy of Engineering the aim of the publication was, as the title suggests, to raise awareness about the dangers of global warming and to highlight the potential solutions being devised by engineers and scientists. The resulting anthology comic book had high production values, mimicking those of a graphic novel, and was created through collaborations between school children, engineers and scientists, comic book artists and illustrators, to imagine, examine and promote solutions to climate change.

The stories in Dreams of a Low Carbon Future draw on key conventions from the science fiction genre that can be divided into two main types, those that show potential dystopian futures and those that demonstrate utopian solutions to the problem of climate change. The cover illustration by Mark Wilkinson is an example of the latter with a utopian future city depicted in a 
manner typical of science fiction illustrations such Dan Dare from the Eagle (see Figure 3.3). However, this cover image is informed by new engineering concepts and is an example of bio-design with organic materials and design principles being used to create a sustainable megacity of the future. This positive view of the future is reflected in stories such as 'Tour of KL2.0 2098' which demonstrate a range of potential solutions to global warming and climate change such as new methods of carbon capture and innovations in energy production. 


\section{TOUR OF KL2.O: 2098 A.D.}

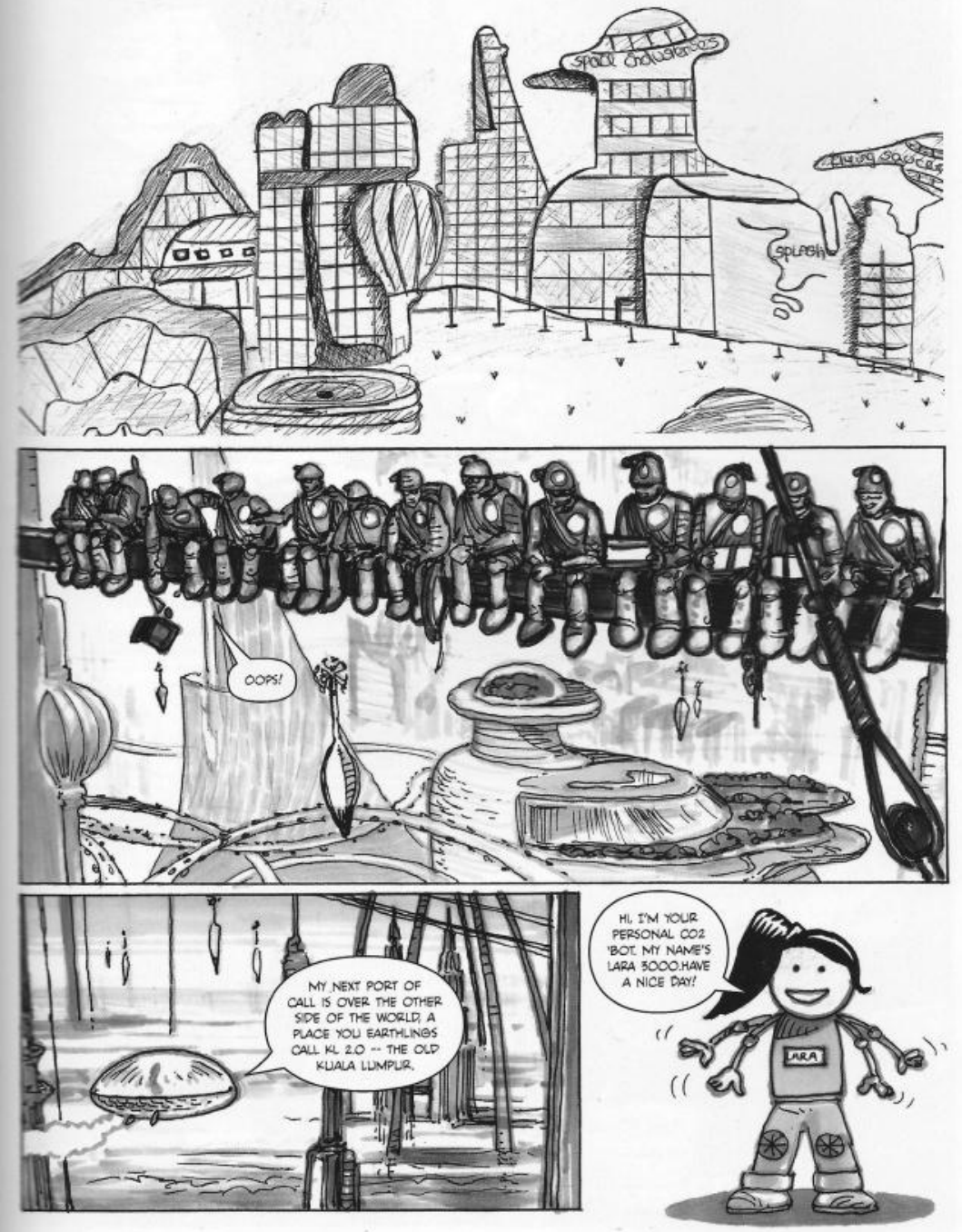

27

Figure 3.6 ‘Tour of KL2.0 2098’ Dreams of a Low Carbon Future 2013

(Created by James Mckay, Nicole Cant and Lara Salih) 
Other stories such as 'Dystopia: Welcome to Judd City - 2045' show the devastation that might be wrought by global warming and the kind of dystopian society that might emerge. In this narrative it is suggested that a ruling elite controls Judd City by exploiting slave workers, called 'subbers' or sub-humans, and by extracting the last remaining fossil fuels through fracking to support a consumerist society in denial of the impact of climate change. 


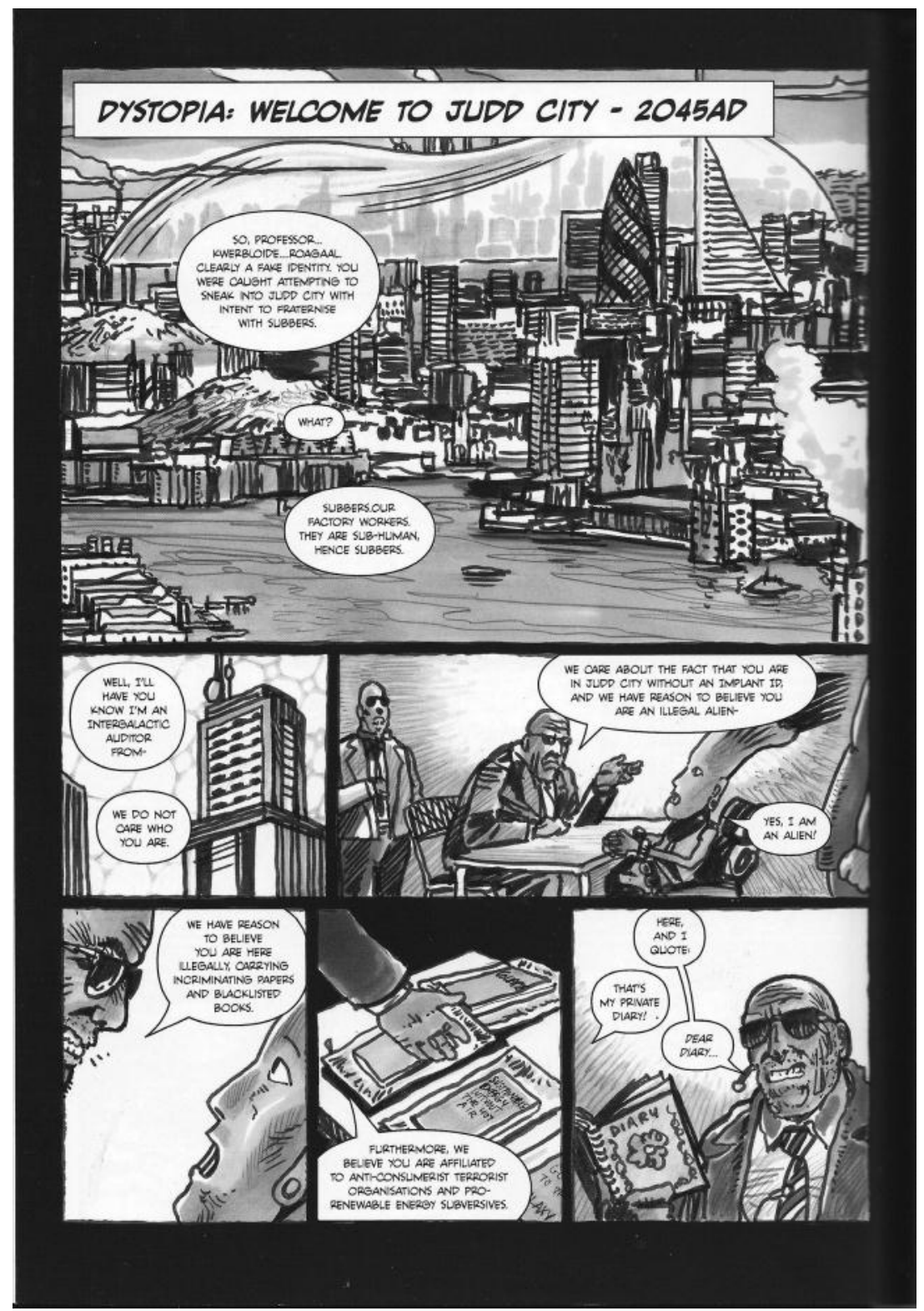

Figure 3.7 'Dystopia: Welcome to Judd City - 2045'Dreams of a Low Carbon Future 2013

(Created by Judd Blackmorre, Lara Salih, Thomas Fletcher, Jasmine Gaunt, Olivia Rogers, James Mackay, Hannah James)

Both of these stories are narrated by Professor Kwerblodie, an alien visitor to Earth. He is introduced in the opening story in Dreams of a Low Carbon 
Future and appears throughout as our guide who is there to provide an objective and external viewpoint to the issues facing the world in this period of crisis. In this first story, he demonstrates how energy operates in a manner similar to the Professor Brittain comic strips discussed earlier by directly addressing the readers and using scientific facts and supporting infographics. Many of the other stories in Dreams of a Low Carbon Future employed devices from the realm of information design such as diagrams, maps and directional arrows to explain the more complex scientific ideas accurately as it was essential that the information provided by the scientists and engineers was presented clearly to the reader.

Information design was used even more extensively in Asteroid Belter: The Newcastle Science Comic, edited by Lydia Wysocki and Paul Thompson and produced as part of the British Science Festival held at Newcastle University in 2013, perhaps because it was aimed at a younger audience than Dreams of a Low Carbon Future. ${ }^{13}$ This intended younger audience was reflected in the simple cartoonish graphic style employed throughout Asteroid Belter and by being printed on newsprint so it looked and felt like a traditional British children's anthology comic book (see Figure 3.2). Asteroid Belter did not focus exclusively on issues of climate change and global warming, which might be predisposed to depictions of dystopian and utopian futures, instead it was a more general science comic book designed to look at a range of scientific subjects and introduce them to new audiences. It explored topics such as botany, geology and quantum physics, with several stories examining health issues often with a rather juvenile sense of humour as demonstrated in titles such as 'A Guinea Pigs' Guide to Cancer Drug Trials' and 'A Day in the Life of a Poo'. Even though representations of dystopia and utopia are mainly absent from Asteroid Belter there are references to other science fiction conventions such as space travel with characters taking a day trip to the moon or going to witness a supernova explosion. Time travel is another well-known science fiction convention employed and is a central theme in three stories in Asteroid Belter, 'Felix and Chuckney in Time Travel Rocks', 'Time travel is ... Awesome' and 'How to Train your Robot', this final example uses the language of information design to incorporate a game for the reader to play and the resulting comic strip can be considered both instructional and entertaining. 


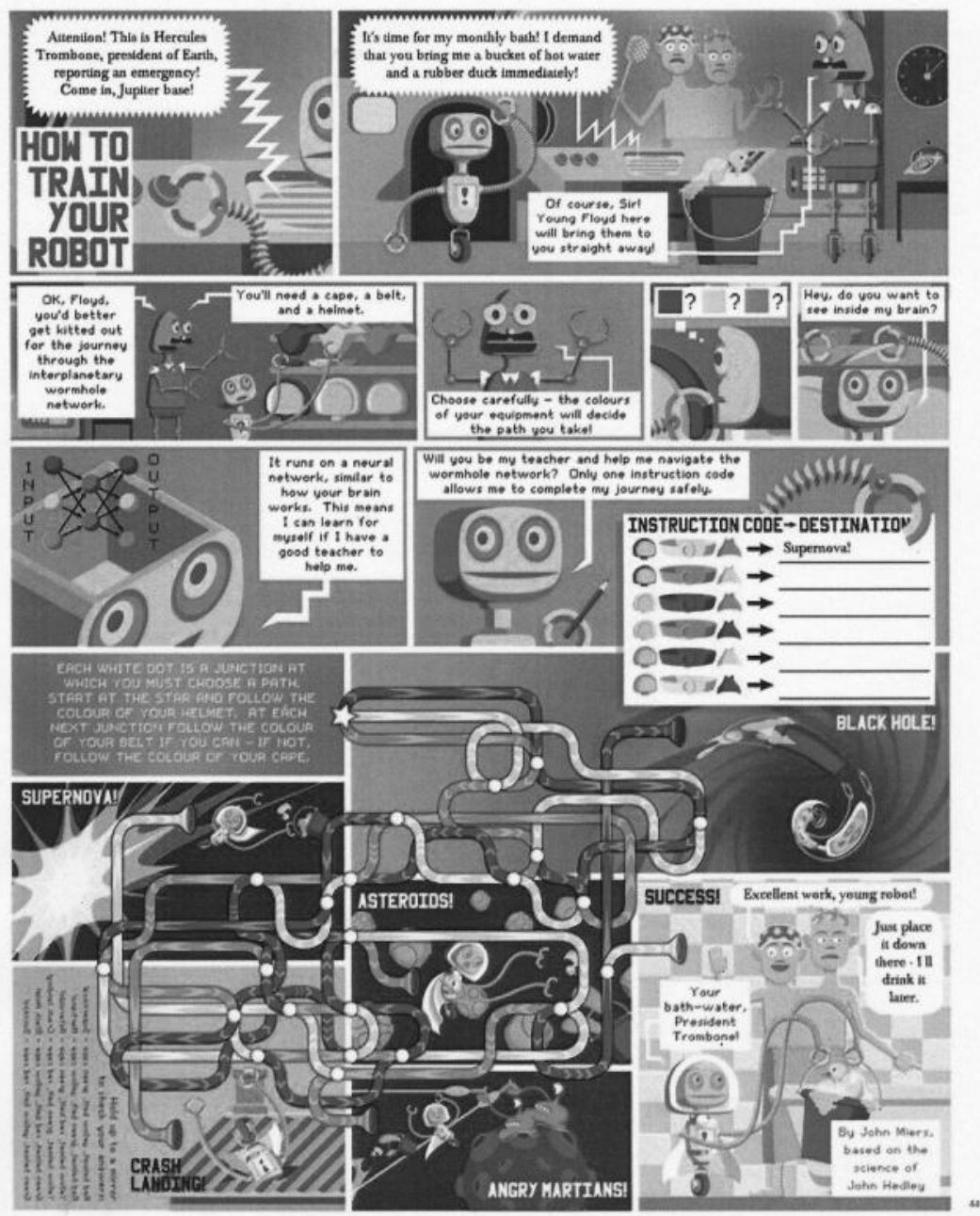

Figure 3.8 'How to Train your Robot' Asteroid Belter: The Newcastle Science Comic 2013

(Comic: John Miers; Science: John Hedley)

One feature that Asteroid Belter and Dreams of a Low Carbon Future share is the convention of the mad scientist or learned professor that has its roots in mainstream science fiction and adventure comic books such Professor Brittain in the Eagle. Such characters appear in several comic strips in Asteroid Belter: in one example a real-life professor, Brian Randell of Newcastle University, explains his research into the history of computing, in another strip Professor Yakka explains how to make a rocket out of a 
plastic bottle, baking soda and vinegar. These examples are relatively straight-forward narratives but the most telling of these kinds of comic strips is titled 'Astoundishing Science' and explicitly deconstructs the notion of the mad scientist.

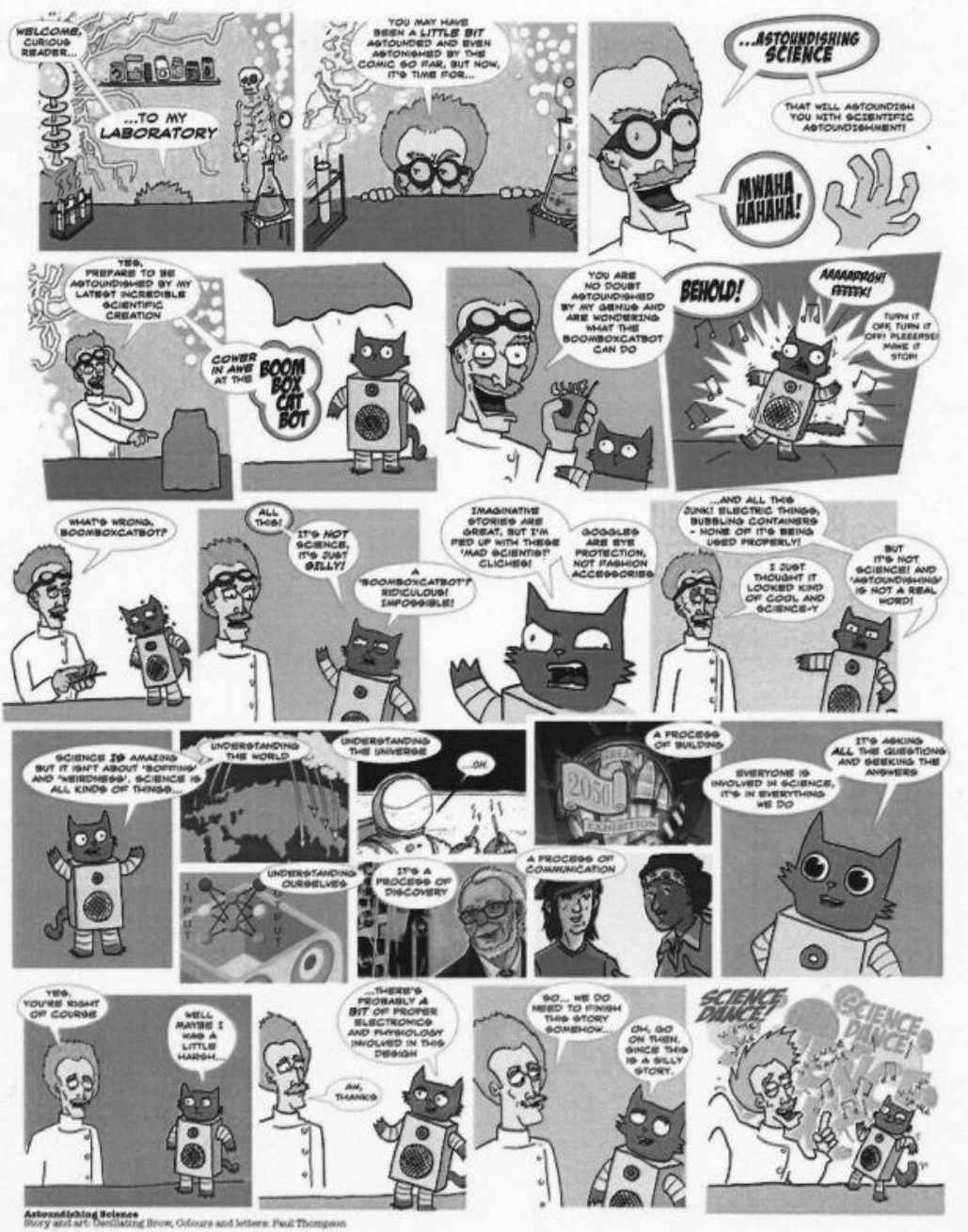

Figure 3.9 'Astoundishing Science’ Asteroid Belter: The Newcastle Science Comic 2013

(Story and art: Oscillating Brow; Colours and letters: Paul Thompson)

The mad scientist invents a cat crossed with a speaker, called Boomboxcatbot, that rebels against him and declares 'It's not science, it's just silly ... Imaginative stories are great, but I'm fed up with these 'mad 
scientist' clichés! .... Science is amazing but it isn't about 'boffins' and weirdness'.

Conventions from the science fiction genre have been adopted and adapted from mainstream comic books to inform the narratives in Asteroid Belter and Dreams of a Low Carbon Future. Will Eisner suggested that instructional comic books should entertain as well as inform and it is possible to argue that in these example of science (fiction) public relations comic books this is achieve by working with established genre conventions using well-understood reader expectations. The focus in this study has been on the use of the science fiction genre in public relations comic books but there is some scope to examine how conventions adopted from other comic book genres; for example, documentary, sports or war, might operate within the realm of public relations.

Where these public relations comic books differ from the mainstream is in how they engage with their audiences. This is achieved in three different ways; the first of these is through the modes of address noted above where the reader is directly addressed by the characters in the stories, a feature that is relatively rare in the mainstream but is commonplace in many public relations comic books. A second feature used to ensure audience engagement is the use of instructional devices drawn from the visual language of information design such as maps, diagrams and directional arrows; these devices also appear occasionally in mainstream entertainment comic books but are much more prevalent in those created for public relations purposes.

A third feature that Asteroid Belter and Dreams of a Low Carbon Future utilize is the fact that they were produced collaboratively with the children who make up their target audience. This feature distinguishes contemporary public relations comic books from those in the past, where the reader was spoken to but did not have its own voice, and ensures that at least some of the target audience are directly engaged with the issues at stake. We have seen that Davidson defined public relation comic books as 'impact comics' because of the way that they have a direct purpose in wanting to promote an idea or a concept and this notion of impact fits well with Eisner's suggestion that these comic books promote attitudinal change. Taken together these ideas of audience engagement, impact and attitudinal change suggest that comic books can be a valuable tool within the public relations profession.

\section{Notes}

\section{References}


Aleixo, Paul and Norris, Claire (2013). 'Planarian Worms, Shock Generators and Apathetic Witnesses: Teaching Psychology and Graphic Novels.' Psychology Teaching Review 19 (1): 36-43.

Alexio, Paul and Summer, Krystina (2017). 'Memory for Biopsychology Material Presented in Comic Book Format.' Journal of Graphic Novels and Comics 8 (1): 79-88.

Chapman, James (2011). British Comics a Cultural History. London: Reaktion Books.

Chapman, Jane, Hoyles, Anna, Kerr, Andrew and Sheriff, Adam (2015). Comics and the Worlds Wars: A Cultural Record. Basingstoke: Palgrave Macmillan.

Davidson, Sol M. (2005). “"The Funnies” Neglected Branch: Special Purpose Comics.' International Journal of Comic Art 7 (2), Fall/Winter: 340-57.

Eisner, Will (1985). Comics and Sequential Art. New York: W. W. Norton.

Fitzgerald, Paul E. (2008). Will Eisner and PS Magazine. New Castle, Pennsylvania: Hermes Press.

'The Funny Papers.' (1933). Fortune, April.

Goulart, Ron (1991). Over 50 Years of American Comic Books. Lincolnwood, IL: Publication International Ltd.

Graham, Richard L. (2011). Government Issue: Comics for the People 1940s-2000s. New York: Abrams Comicarts.

Hatfield, Charles (2012). Hand of Fire: The Comics Art of Jack Kirby. Jackson, MS: University Press of Mississippi.

Holland, Steve (2006). Look and Learn a History of the Children's Magazine. Available at www.lookandlearn.com/history/Look-and-Learn-History.pdf.

Mickwitz, Nina (2016). Documentary Comics: Graphic Truth-Telling in a Skeptical Age. Baisingstoke: Palgrave Macmillian.

Moebius (Jean Giruad) (1988). 'Upon a Star.' in Moebius (Jean Giruad), Moebius 1:

The Collected Fantasies of Jean Giraud. (English Translation by JeanMarc and Randy Lofficier). London: Titan Books. (Unpaginated).

Murray, Chris (2017). The British Superhero. Jackson, MS: University Press of Mississippi.

Sabin, Roger (1993). Adult Comics: An Introduction. London: Routledge.

Smith, Matthew J. and Duncan, Randy (2009). The Power of Comics. New York: Continuum International Publishing Group.

Smith, Matthew J. and Duncan, Randy (Eds.) (2017). The Secret Origins of Comics Studies. Baisingstoke:

Routledge.

${ }^{1}$ The Graphic Medicine website (www.graphicmedicine.org/) was founded by Dr Ian Williams in 2007. In the last decade the Graphic Medicine network has grown extensively and runs regular international conferences and has its own book series published by Penn State University Press.

${ }^{2}$ For an overview of the emergence of Comics Studies as an academic discipline see Matthew J. Smith and Randy Duncan (Eds.) (2017) The Secret Origins of Comics Studies. Basingstoke: Routledge. 
${ }^{3}$ Davidson's article is the only substantial study of the topic and was in part written to note that he had donated his substantial personal collection of such comics to the University of Florida's George A. Smathers Libraries. Such comics are by their very nature ephemeral and it is only through building personal collections or donations by other collectors like Davidson that the topic can be studies in any depth. A more recent study from 2011, Richard L. Graham's Government Issue: Comics for the People 1940s-2000s, examines some of this material in detail but as the title suggests it only addresses comic books published by the American government and therefore provides only a partial account of the field.

${ }^{4}$ Valiant, 20th February1971, IPC Magazine Ltd.

${ }^{5}$ Downey served with the Royal Marines from 1960 to 1978. Details recorded in an oral history project for the Imperial War Museum. www.iwm.org.uk/collections/item/object/80032295.

6 The entire run of PS Magazine the Preventative Maintenance Monthly has been scanned and made available for researchers by Virginia Commonwealth University Library Digital Collections. http://dig.library.vcu.edu/cdm/landingpage/collection/psm

${ }^{7}$ For a discussion of the psychology behind the educational potential for comic books see Paul Aleixo and Krystina Sumner (2017) 'Memory for Biopsychology Material Presented in Comic Book Format.' Journal of Graphic Novels and Comics 8 (1), pp. 79-88 and Paul Aleixo and Claire Norris (2013) 'Planarian Worms, Shock Generators and Apathetic Witnesses: Teaching Psychology and Graphic Novels.’ Psychology Teaching Review 19 (1), pp. 3643.

${ }^{8}$ The ideas examined here are based on a paper titled 'Look and Learn from a World of Wonder' delivered at Science, Imagination, and the Illustration of Knowledge the 4th International Illustration Symposium in Oxford in 2013.

${ }^{9}$ Look and Learn was published between 1962 and 1982. Another boy's comic book Ranger (1965-66) which included the science fiction story 'The Rise and Fall of the Trigan Empire' (later simply titled 'The Trigan Empire') was merged with Look and Learn in 1966. Another children's magazine World of Wonder (1970-75) was merged with Look and Learn in 1975. The Eagle was published between 1950 and 1969 when it was incorporated with another boy's comic book Lion. 'Dan Dare: Pilot of the Future' was dropped as the lead story of the Eagle in the mid-1960s. The Eagle was revived in 1982 and carried on with Dan Dare as a central character until its final demise in 1994.

10 The relationship between British superheroes such as Dan Dare and the social discourses surrounding science fiction and technology are explored in detail in Chris Murray (2017) The British Superhero. Jackson, MS: University Press of Mississippi.

1 As reported in hansard.millbanksystems.com/commons/1982/feb/15/defence\#column_62

12 For information on Dreams of a Low Carbon Future see https://cdt.engineering.leeds.ac.uk/dtc-low-carbontechnologies/research/DreamsofaLowCarbonFuture.shtml. In November 2016 McKay and Dickinson released A Dream of a Low Carbon Future a revised and refined version of the original comic book focused on the single idea of depicting a sustainable world for the future.

13 For information on Asteroid Belter: The Newcastle Science Comic see http://newcastlesciencecomic.blogspot.co.uk/. 
